\title{
Correction: Precision weighting of cortical unsigned prediction error signals benefits learning, is mediated by dopamine, and is impaired in psychosis
}

\author{
J. Haarsma - P. C. Fletcher • J. D. Griffin - H. J. Taverne - H. Ziauddeen (1) - T. J. Spencer $\cdot$ C. Miller $\cdot$ T. Katthagen $\cdot$ \\ I. Goodyer · K. M. J. Diederen · G. K. Murray (D)
}

Published online: 14 October 2020

(c) The Author(s) 2020. This article is published with open access

Correction to: Molecular Psychiatry

https://doi.org/10.1038/s41380-020-0803-8

published online 24 June 2020

Following publication of this article, the authors noticed an error in Fig. 6. In the original figure, the calculation of the positive symptoms score for the graph in panel B was different to the calculation described in the text, and the scale bar on the $y$-axis of the graph in panel B was incorrect. Additionally, the colours on the data points in Fig. 6B were unclear due to a production error. Figure 6 has now been replaced with a corrected version. The original, incorrect version of Fig. 6 is displayed below for reference.

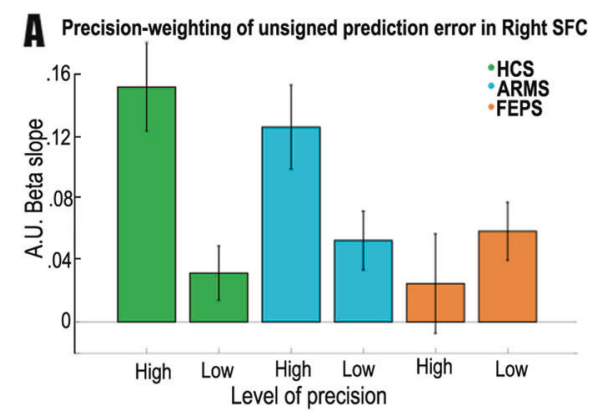

Fig. 6 .

\begin{abstract}
Open Access This article is licensed under a Creative Commons Attribution 4.0 International License, which permits use, sharing, adaptation, distribution and reproduction in any medium or format, as long as you give appropriate credit to the original author(s) and the source, provide a link to the Creative Commons license, and indicate if changes were made. The images or other third party material in this article are included in the article's Creative Commons license, unless indicated otherwise in a credit line to the material. If material is not included in the article's Creative Commons license and your intended use is not permitted by statutory regulation or exceeds the permitted use, you will need to obtain permission directly from the copyright holder. To view a copy of this license, visit http://creativecommons. org/licenses/by/4.0/.
\end{abstract}

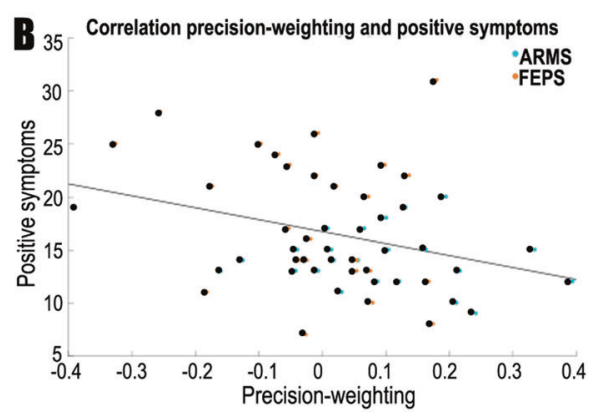

